$\xi=-1$

\title{
Effects of Soluble Lignocellulose Substances of Wood Particles on the Mechanical Properties of Lightweight Concrete
}

\author{
Aqil M. ALmusawi ${ }^{1 *}$, Zaid A. ALzaidi ${ }^{1}$ and Tamara A. Qasim ${ }^{2}$ \\ ${ }^{1}$ Roads and Transport department, University of Al-Qadisiyah, Diwanyah city, Iraq. \\ ${ }_{2}^{2}$ Civil Engineering Department, University of Mustansiriyah, Baghdad, Iraq \\ *Corresponding author E-mail: aqil.kadhim@qu.edu.iq
}

\begin{abstract}
Recent trends in lightweight concrete manufacturing have led to a proliferation of studies demonstrating that wood aggregates can be used to produce sustainable green concrete composites. However, wood particles contain soluble substances (saccharides), which have a significant effect on the setting time of Portland cement. To attain a better understanding of this, two types of wood were treated in boiling water. After the treatment process, the resulting water ("boiling water of wood") was used to study its effect on the initial setting time of Portland cement. The mechanical properties and the density were also investigated for concrete mixtures consisting of $0,5,7.5$, and $10 \%$ treated wood particles (weight replacement from coarse aggregate). As a result, the effect of the wood's soluble substances was determined and the optimum mix proportion was chosen for achieving the minimum nominal density and the best mechanical properties.
\end{abstract}

Keywords: Characterization; Lightweight Concrete; Mechanical Properties; Soluble Lignocellulose Substances; Wood Particles.

\section{Introduction}

The last few decades have seen a growing trend of producing wood-concrete composites with sufficient mechanical properties and superior physical performance (density, thermal and acoustic insulation) $[1,2,3]$. Waste from the wood processing industry can be used to produce lightweight concrete as a sustainable, ecological, recyclable and inexpensive building material [4,5]. Small wood particles are regarded as a solid waste which can be used as a filler material. However, the challenge associated with this technology involves the incompatibility between the wood particles and the concrete components [6,7]. The main obstacles encountered during many experiments with wood-concrete products are the compressibility of the wood particles inside the hardened concrete due to its low rigidity [8], as well as the incompatibility caused by the soluble substances during the fresh phase [9]. These organic soluble substances (almost carbohydrates) may have strong inhibitory effects on the hydration of ordinary Portland Cement $[8,10]$. In fact, they can increase the $\mathrm{PH}$ of the cement mixture to more than 12.5 due to the formation of $\mathrm{Ca}(\mathrm{OH}) 2$, which facilitates the dissolution of the low molecular weight substances inside the wood particles [11,12]. Therefore, the wood particles has to be treated before being used in the concrete composite. The hot water extraction (HWE) process is one of the common treating methods used for reducing the effect of soluble substances, as well as for increasing the volume stability and surface roughness $[13,14]$. The extracted boiling water has a clear brown color for soft and hard wood (redwood), and its main compounds are lignin, tannins, phenol, acid resin and volatile fatty acids [15]. The lignocellulose component contains different saccharides with varying softening temperatures and solubility levels in water. Therefore, the saccharide concentrations in the boiling water can be changed according to the time and the temperature, as well as the wood concentration. These saccharides can have an important effect on cement hydration, either by retarding the formation of calcium silicate hydrate $(\mathrm{C}-\mathrm{S}-\mathrm{H})$ or by forming a semipermeable membrane around the cement particles [8]. This research provides an exciting opportunity to advance our knowledge about their chemical compositions and their concentrations in boiling water. The investigation of these, along with their retarding effect on cement hydration, is the primary focus of the first section of this research.

The second part of this research is a discussion of the possibility of using treated wood particles (soft wood and redwood) as a filler in concrete composites. These particles were fully saturated by water in order to: 1- keep the water/cement ratio constant in the mixture, which was necessary for the hydration process [16]; 2minimize the extraction of the residual soluble substances from inside the wood particles [17]; 3- increase the possibility of enveloping the exterior surface of wet particles with a layer of dry cement, to improve the interface bonding with the other components (fine and coarse aggregate); and 4- increase the wood density by more than double due to water absorption, in order to reduce the segregation of wood particles during the mixing process [18]. Segregation can also be controlled by reducing the workability to a minimum level. In contrast, using dry wood particles represents a very poor choice; even when adding adequate water content (W/c + wood absorption), the dry wood particles absorb the water from the mixture slowly, and thus the free water increases the workability, causing segregation (floating) of the particles on the upper surface throughout the mixing and placing processes.

\section{Materials and Sample Preparation}

The materials used in this research were characterized according to the standard specification protocols in order to define the features necessary to directly affect the results. 


\subsection{Materials}

The concrete mixture mainly consisted of cement, which worked as a binder after the hydration process, as well as fine and coarse aggregates, which were responsible for the concrete's strength Two types of wood particles were used as a partial replacement for the coarse aggregate proportion, and tap water was used in the mixing process and the curing of the concrete samples.

\subsubsection{Cement}

High early strength Portland cement (Type III) was used to manufacture all the concrete samples. This type of cement was chosen to facilitate the detection of the effect of boiling water of wood particles on its initial setting time, and its increase in strength due to the cement hydration process.

\subsubsection{Fine and Coarse Aggregates}

Local aggregates resourced from a river were used, the chemical and physical properties of which were tested in the laboratory of the Civil Engineering Department. The coarse aggregate had a maximum size of $10 \mathrm{~mm}$ and a modulus of finesse of 2.7 , which represented a good size grade according to the standard test of ASTM (C136/ C136M-14). Also, the sieve analysis proved that the fine aggregate had a good size distribution according to the same standard test of ASTM (C136/ C136M-14). These two types of aggregates were washed with tap water to thoroughly clean their surfaces and to obtain fully saturated particles.

\subsubsection{Soft Wood and Redwood}

Two types of wood were chopped and treated with hot water. Both types of wood particles (soft wood and redwood) were soaked in water for 24 hours, then boiled at $160-180^{\circ} \mathrm{C}$ for 2 hours. The wood particles were filtered and kept saturated until they were used to produce the wood-concrete samples. These particles, which had a maximum size of $10 \mathrm{~mm}$, were used as a partial replacement for the coarse aggregate. The residual boiling water was chemically analysed and used instead of tap water in the concrete mixtures to study its effect on the setting time of hydraulic cement, as shown in Figure 1.

\subsubsection{Water}

Normal (tap) water was used to evaluate the setting time, as well as to prepare the reference concrete samples, while the boiling water was only used with the cement to investigate the effect of soluble wood substances on the setting time of Portland cement.

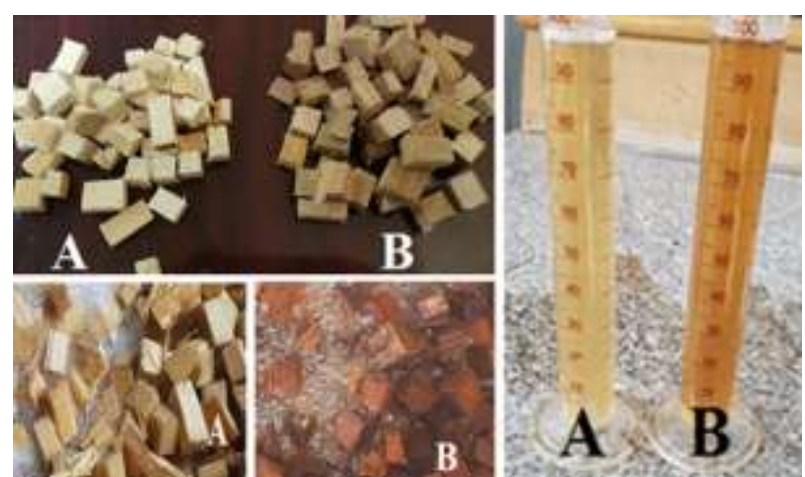

Fig. 1: Images of wood particles before and after treatment, and the extracted water. (A): soft wood. (B): redwood.

\subsection{Sample Preparation}

A reference sample was prepared with a mix proportion of 1:2: 4 (cement: sand: gravel) without wood particles. These components were mixed with a minimum water content of $30 \%$ wt. of cement. The admixture of high range water reduction (EPSILONE HP 580) was used in order to obtain high strength and good workability. The average slump test result obtained was $50 \mp 25 \mathrm{~mm}$ when $1 \%$ wt. of this admixture was used as a percentage of cement weight. Then, two series of concrete composites were produced. The first series contained the soft wood particles in proportions of 5, 7.5 and $10 \%$ wt. as a partial replacement for coarse aggregate. The second contained the redwood particles in proportions of $5,7.5$ and $10 \%$ wt. as a partial replacement for coarse aggregate. 70 cubic samples of (150 $\mathrm{mm}$ for each side) were placed to investigate the compressive strength at 7 and 28 days, as shown in Figure 2 . One hollow wood-concrete brick was manufactured in order to provide a realistic example of the final product application.
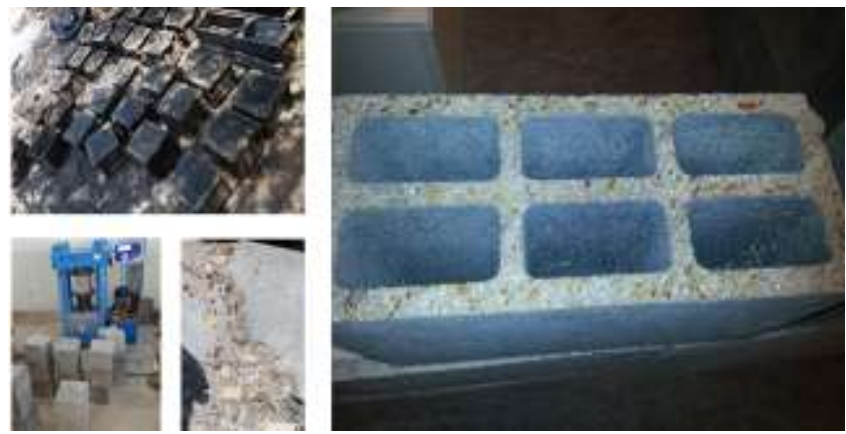

Fig. 2: Placing, testing, and final product of wood-concrete composite.

\section{Results and Discussions}

In this section, the chemical components of the boiling water, the effects of the boiling water on the setting time of hydraulic cement, and the effects of wood particles on the concrete density and compressive strength, were reviewed and discussed.

\subsection{Chemical Compositions of the Boiling Water of Wood Particles}

A chemical analysis test was conducted to determine the concentration of monomeric sugars in the boiling water of wood particles, as listed in Table 1.

Table 1: Concentrations of monomeric sugars in the boiling water of wood particles.

\begin{tabular}{|l|l|l|l|l|l|l|}
\hline \multirow{2}{*}{$\begin{array}{l}\text { Boiling } \\
\text { water }\end{array}$} & \multicolumn{5}{|c|}{ Concentration of monomeric sugars (mg/ml) } \\
\cline { 2 - 7 } & $\begin{array}{l}\text { Glu- } \\
\text { cose }\end{array}$ & $\begin{array}{l}\text { Man- } \\
\text { nose }\end{array}$ & $\begin{array}{l}\text { Galac- } \\
\text { tose }\end{array}$ & $\begin{array}{l}\text { Arabi- } \\
\text { nose }\end{array}$ & $\begin{array}{l}\text { Xy- } \\
\text { lose }\end{array}$ & $\begin{array}{l}\text { Total } \\
\text { Sug- } \\
\text { ars }\end{array}$ \\
\hline $\begin{array}{l}\text { Soft } \\
\text { wood }\end{array}$ & 0.011 & 0.018 & 0.072 & - & 0.009 & 0.167 \\
\hline $\begin{array}{l}\text { Red- } \\
\text { wood }\end{array}$ & 0.015 & 0.013 & 0.085 & - & 0.012 & 0.188 \\
\hline
\end{tabular}

The chemical reaction of lignocellulose substances with cement compounds is mainly dependent on the type of cement, i.e., the quantities of the cement's constituents. These types of chemical reactions are still unknown due to complex mechanisms that depend on many factors. For example, glucose reacts first with tricalcium aluminate $\left(\mathrm{C}_{3} \mathrm{~A}\right)$, and then the residual glucose can have the effect of retarding the reaction of tricalcium silicate $\left(\mathrm{C}_{3} \mathrm{~S}\right)$ [19].

\subsection{Setting Time of Hydraulic Cement}

The optimum consistency of cement paste was tested using Vicat apparatus for many trials of water/cement ratios in order to determine the optimum ratio. The results indicated that the optimum w/c ratio was 30.5 as a percentage of cement weight. Then, three types of water were added to dry cement in order to study their effects on the setting time of hydraulic cement. According to the ASTM (C191-04), three samples of normal (tap) water, boiling water of soft wood, and boiling water of redwood were prepared, 
and then tested at the same times and conditions, as shown in Figure 3 .

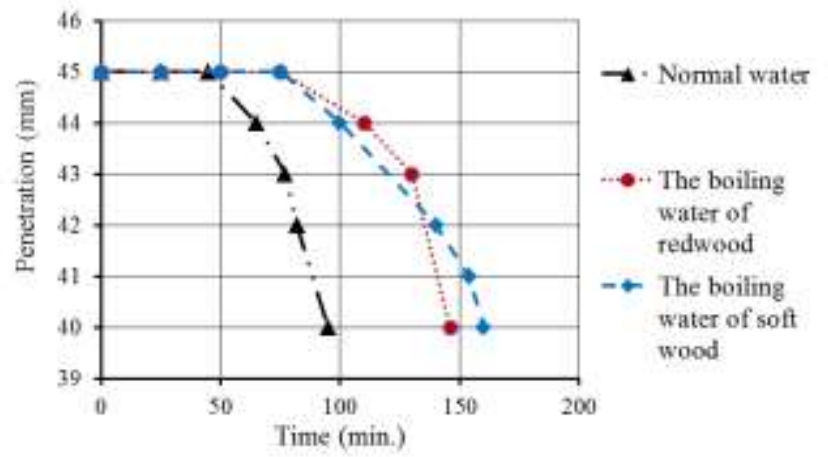

Fig. 3: Effects of boiling water of wood particles on setting time of cement.

The setting time of hydraulic cement was affected by the water type. The initial setting time was 95, 146 and 160 minutes for the normal water, boiling water of redwood, and boiling water of soft wood, respectively. The extracted soluble substances from the wood particles due to the water and the effect of elevated temperature inhibited C-S-H formation, thus retarding the setting of the cement paste [20]. These results concurred with several studies on the effects of sucrose and glucose which have concluded that, depending on their concentration, they can not only alter the setting of cement paste for several days, but also the micro-structure of C-S-H $[9,21]$.

\subsection{Wood-Concrete Density}

After 25 days of curing, the samples were removed from the water tank and dried in an open area for 48 hours, and then oven-dried at $105{ }^{\circ} \mathrm{C}$ for 24 hours. The bulk density of each sample was then calculated by measuring the mass with an electrical balance of 0.1 $\mathrm{gm}$. of accuracy, then dividing that by the measured volume after taking three distance measurements for each side with a digital caliber (Vernier scale), as indicated in Figure 4.

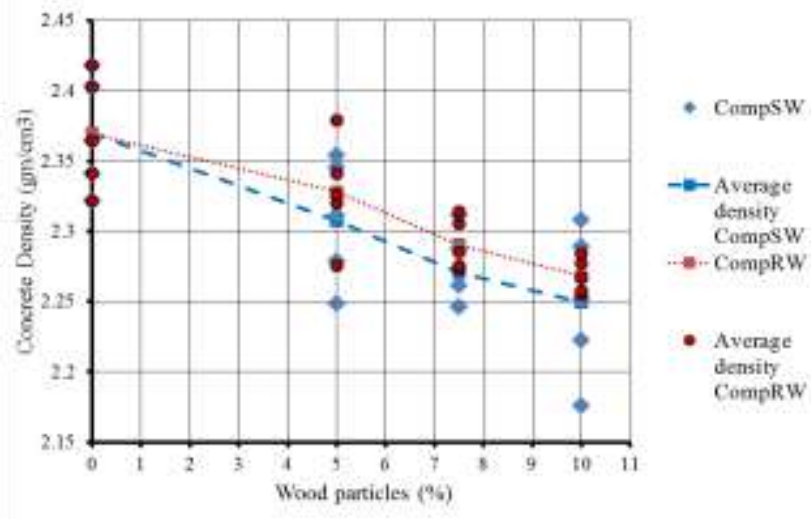

Fig. 4: Concrete density corresponding to wood particle proportions.

Figure 4 provides the experimental data on the density, which decreased when the wood particle replacement percentage was increased. When the wood particle replacement was increased to $10 \%$ wt., the composite density of the redwood and soft wood decreased by about $4.2 \%$ and $5 \%$ respectively, compared to the coarse aggregate. The concrete composite consisting of redwood particles exhibited a slightly higher density than the concrete with soft wood particles. In fact, the redwood had fewer voids than the soft wood, while the soft wood contained more lignin, which can restrict the volume change at normal temperature [22]. Wood cell walls are mainly composed of lignin, which works as an impermeable layer, as well as a cementing agent, giving the wood cell its rigidity and compressive strength. Treating wood particles with boiling water leads to softening, and dissolving the soluble con- stituents causes an inverse behaviour for these wood types. After applying hot water extraction (HWE) technology, the redwood became more volume stable and had less water absorption than the soft wood $[23,24]$.

\subsection{Compressive Strength}

Samples of different types of wood particles and different proportions of coarse aggregate replacement were tested for compressive strength according to the ASTM (C39) standard with a universal machine. The compressive strengths at 7 and 28 days were recorded for 70 cubic samples, while the average was considered for every 5 samples of the same components, as shown in Figure 5.
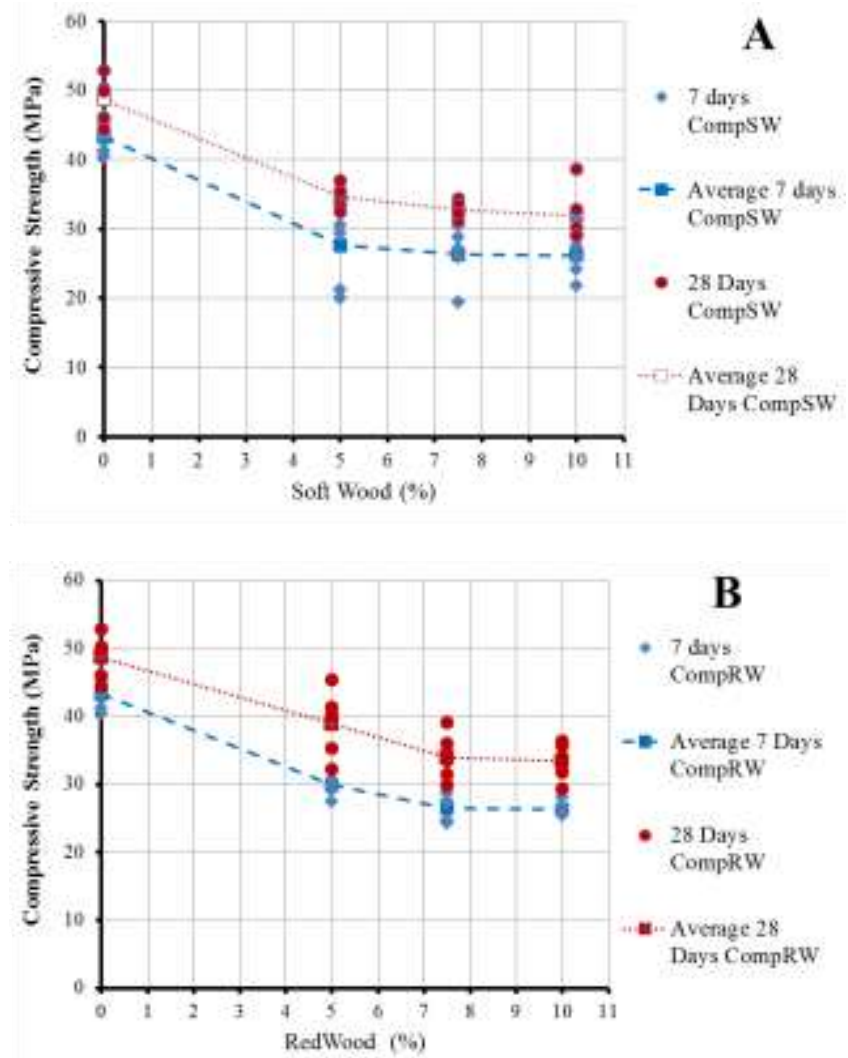

Fig. 5: Concrete compressive strength corresponding to wood particle percentage (A) at 7 days and (B) at 28 days.

The reference samples ( $0 \%$ wood particles) exhibited very good compressive strength at 7 days due to the use of high early strength cement, as well as the use of the minimum w/c ratio. Thus, the compressive strength of these samples only increased by $12.4 \%$ at 28 days, compared to their resistance at 7 days. On the other hand, the concrete consisting of wood particles had an increase in compressive strength of more than $25 \%$ at 28 days, compared with the resistance at 7 days. These results demonstrate the effect of wood particles on the hydration process at early age strength. The treatment of wood particles was not very efficient of extracting all the soluble substances, which can affect the tricalicium silicate (C3S) reaction. Indeed, C3S is responsible for high early strength while dicalcium silicate $(\mathrm{C} 2 \mathrm{~S})$ is responsible for the final strength, and both of them generate calcium silicate hydrate $(\mathrm{C}-\mathrm{S}-\mathrm{H})$, which is similar to the mineral tobermorite. In fact, sucrose does not react with tricalcium aluminate $(\mathrm{C} 3 \mathrm{~A})$ but can react with the more rapidly strengthening compound (C3S) to enhance the formation of ettringite at an early stage [25]. Similar to the gypsum quantity effect, increasing the ettringite formation leads to great expansion, which can cause an increase in the generation of micro-cracks. The effects of these micro-cracks, as well as the porous structure caused by the $(\mathrm{C} 3 \mathrm{~A})$ reaction, can be reduced by the new hydration products of $(\mathrm{C} 2 \mathrm{~S})$. 
The composites of redwood particles had better compressive strength than the composites of soft wood particles. As shown in Figure 5, a significant decrease in strength occurred when $5 \%$ of wood particles were added, as compared with the strength of the reference composite, while a slight decrease in compressive strength was observed when the wood proportion was increased.

In order to investigate the double effect that adding wood particles had on the physical and mechanical properties of the conventional concrete mixture (1:2:4), the specific compressive strength for each mix proportion was calculated by dividing the compressive strength by the density, as shown in Table 2 . There was no significant decrease in specific compressive strength when the wood replacement was increased up to $10 \%$, due to the decrease in density.

Table 2: Physical and Mechanical Properties of Wood-Concrete Composites.

\begin{tabular}{|c|c|c|c|c|c|c|}
\hline Sample & Wood type & $\begin{array}{l}\text { Weight frac- } \\
\text { tion }(\%)\end{array}$ & Slump $(\mathrm{mm})$ & $\begin{array}{c}\text { Bulk density } \\
\left(\mathrm{gm} / \mathrm{cm}^{3}\right)\end{array}$ & $\begin{array}{c}\text { Compressive } \\
\text { strength at } 28 \text { days } \\
(\mathrm{MPa})\end{array}$ & $\begin{array}{l}\text { Specific compres- } \\
\text { sive strength }\end{array}$ \\
\hline Ref,0 & - & 0 & 50 & 2.369 & 48.633 & 20.523 \\
\hline CompSW,5 & \multirow{3}{*}{ Soft wood } & 5 & 62 & 2.307 & 34.593 & 14.991 \\
\hline CompSW,7.5 & & 7.5 & 68 & 2.270 & 32.701 & 14.402 \\
\hline CompSW,10 & & 10 & 75 & 2.249 & 31.921 & 14.191 \\
\hline CompRW,5 & \multirow{3}{*}{ Redwood } & 5 & 60 & 2.328 & 38.873 & 16.695 \\
\hline CompRW,7.5 & & 7.5 & 70 & 2.290 & 33.962 & 14.826 \\
\hline CompRW,10 & & 10 & 73 & 2.268 & 33.428 & 14.738 \\
\hline
\end{tabular}

This behaviour enhanced our curiosity about whether increasing the wood proportion even more would improve the physical properties (density, acoustic and thermal insulation) of the concrete mixture yet again.

\section{Conclusion}

Returning to the questions posed at the beginning of this research about the effects of wood particles on the density, setting time and compressive strength of concrete, it is now possible to state the following interesting results:

1-The density decreased when the wood particle replacement was increased, and the concrete composite of redwood particles had a higher density than the concrete of soft wood particles.

2-The setting time of hydraulic cement was affected by water type. The initial setting time was 95, 146 and 160 minutes when using normal water, the boiling water of redwood, and the boiling water of soft wood, respectively. It was also confirmed that the soluble substances of wood particles inhibit C-S-H formation, thus retarding the setting of cement paste.

3-The composites containing redwood particles had better compressive strength than the composites with soft wood particles. However, a significant decrease in strength occurred when $5 \%$ of wood particles were added, when compared with the strength of the reference composite, and then a slight decrease in compressive strength was observed when the wood proportion was increased to $10 \%$ wt.

4-There was no significant decrease in specific compressive strength when the wood replacement was increased up to $10 \%$ due to the decrease in density. This behaviour supports our idea to investigate whether increasing the wood proportion even more would help to achieve additional improvements to the physical properties (density, acoustic and thermal insulation) of concrete mixtures.

Further research should therefore concentrate on the physical properties of concrete (acoustic and thermal insulation), as well as the use of hollow wood-concrete blocks, for bearing wall applications.

\section{Acknowledgement}

The authors would like to thank 1) the Ministry of Higher Education; and 2) the University of Al-Qadisiyah (Iraq) for their financial support.

\section{References}

[1] Clouston, Peggi, Leander A. Bathon, and Alexander Schreyer "Shear and bending performance of a novel wood-concrete compo- site system." Journal of Structural Engineering 131.9 (2005): 1404 1412.

[2] Gutkowski, R., et al. "Laboratory tests of composite woodconcrete beams." Construction and Building Materials 22.6 (2008) 1059-1066.

[3] Gauthier, Daniel. "Composite wood-concrete building member." U.S. Patent No. 5,561,957. 8 Oct. 1996.

[4] Raut, S. P., R. V. Ralegaonkar, and S. A. Mandavgane. "Development of sustainable construction material using industrial and agricultural solid waste: A review of waste-create bricks." Construction and building materials 25.10 (2011): 4037-4042.

[5] Al Rim, K., et al. "Influence of the proportion of wood on the thermal and mechanical performances of clay-cement-wood composites." Cement and Concrete Composites 21.4 (1999): 269-276.

[6] Meyer, Christian. "The greening of the concrete industry." Cement and concrete composites 31.8 (2009): 601-605.

[7] Jorge, F. C., C. Pereira, and J. M. F. Ferreira. "Wood-cement composites: a review." Holz als Roh-und Werkstoff 62.5 (2004): 370377.

[8] Bederina, M., et al. "Effect of the treatment of wood shavings on the physico-mechanical characteristics of wood sand concretes." Construction and Building Materials 23.3 (2009): 1311-1315.

[9] Kochova, K., et al. "Effect of saccharides on the hydration of ordinary Portland cement." Construction and Building Materials 150 (2017): 268-275

[10] Merkley, Donald J., and Caidian Luo. "Fiber cement composite materials using cellulose fibers loaded with inorganic and/or organic substances." U.S. Patent No. 6,872,246. 29 Mar. 2005.

[11] Sandermann, W. "Studies on mineral-bonded wood materials. IV A short test of the aptitudes of woods for cement-bonded materials." Holzforschung 18 (1964): 53-59.

[12] Evans, Philip D. "Wood-cement composites in the Asia-Pacific region." (2002).

[13] Govin, Alexandre, Arnaud Peschard, and René Guyonnet. "Modification of cement hydration at early ages by natural and heated wood." Cement and concrete composites 28.1 (2006): 12-20.

[14] Almusawi, A., et al. "Proposal of manufacturing and characterization test of binderless hemp shive composite." International Biodeterioration \& Biodegradation 115 (2016): 302-307.

[15] Svensson, Henric. "Characterization, toxicity and treatment of wood leachate generated outdoors by the wood-based industry. " Diss. Linnaeus University Press, 2014.

[16] Frybort, Stephan, et al. "Cement bonded composites-A mechanical review." BioResources 3.2 (2008): 602-626.

[17] Hsu, W. E., et al. "Chemical and physical changes required for producing dimensionally stable wood-based composites." Wood Science and Technology 22.3 (1988): 281-289.

[18] Ferrara, Liberato, Yon-Dong Park, and Surendra P. Shah. "A method for mix-design of fiber-reinforced self-compacting concrete." Cement and Concrete Research 37.6 (2007): 957-971.

[19] De La Grée, GCH Doudart, Q. L. Yu, and H. J. H. Brouwers. "The effect of glucose on the hydration kinetics of ordinary Portland cement." 1st International conference on bio-based building materials. 2015.

[20] Erakhrumen, A. A., et al. "Selected physico-mechanical properties of cement-bonded particleboard made from pine (Pinus caribaea M.) 
sawdust-coir (Cocos nucifera L.) mixture." Scientific Research and Essay 3.5 (2008): 197-203.

[21] Juenger, Maria C. Garci, and Hamlin M. Jennings. "New insights into the effects of sugar on the hydration and microstructure of cement pastes." Cement and concrete research 32.3 (2002): 393-399.

[22] Schroeder, Herbert A. "Shrinking and swelling differences between hardwoods and softwoods." Wood and Fiber Science 4.1 (2007): 20-25.

[23] Pelaez-Samaniego, Manuel Raul, et al. "Effect of hot water extracted hardwood and softwood chips on particleboard properties." Holzforschung 68.7 (2014): 807-815.

[24] Garrote, G., H. Dominguez, and J. C. Parajo. "Hydrothermal processing of lignocellulosic materials." European Journal of Wood and Wood Products 57.3 (1999): 191-202.

[25] Bishop, Maximilienne, and Andrew R. Barron. "Cement hydration inhibition with sucrose, tartaric acid, and lignosulfonate: analytical and spectroscopic study." Industrial \& engineering chemistry research 45.21 (2006): 7042-7049. 